\title{
QUALIDADE DE VIDA NO TRABALHO EM UMA EMPRESA DE MATERIAIS DE CONSTRUÇÃO CIVIL DE PRESIDENTE PRUDENTE/SP
}

Amanda Oliveira de Souza, Pamela dos Santos Ricci, Lucas Luciano Fernandes Faria, Sabrina Paulo de Souza, Renato Carlos Camacho Neves, Valdecir Cahoni Rodrigues, Gustavo Yuho Endo

Universidade do Oeste Paulista - UNOESTE, Cursos de Gestão de Recursos Humanos e Administração, Presidente Prudente,SP. E-mail: gustavo@unoeste.br

\section{RESUMO}

Este estudo procurou analisar a qualidade de vida no trabalho (QVT) oferecida por uma empresa do segmento de materiais para construção civil, com base em conceitos teóricos de QVT. O intuito foi analisar se na empresa objeto de estudo possuem práticas de QVT e na falta delas propor melhorias. A abordagem metodológica utilizada neste estudo é o relato técnico-científico, sendo definido como produto final de um trabalho, sendo uma pesquisa aplicada ou produção técnica que vai descrever as experiências vivenciadas na organização com base científica e metodológico. Foi possível observar que a empresa oferece práticas de QVT, mas que não são suficientes para atender as necessidades dos colaboradores e, por esse motivo foram propostas as ações como a padronização dos benefícios, regulamentação da jornada de trabalho, padronização de EPIs, plano de ginástica laboral, plano de cargos e carreira, pesquisa de clima organizacional e palestras motivacionais.

Palavras-Chaves: Gestão de pessoas. Qualidade de vida no trabalho. Saúde do trabalhador.

\section{QUALITY OF LIFE AT WORK IN A COMPANY OF CIVIL CONSTRUCTION MATERIALS OF PRESIDENTE PRUDENTE/SP.}

\begin{abstract}
This study aimed to analyze the quality of life at work (QLW) offered by a company in the construction materials segment, based on QLW theoretical concepts. The purpose of this study was to analyze whether QLW practices exist in the company under study and in the absence of them to propose improvements. The methodological approach used in this study is the technical-scientific report, being defined as the final product of a work, being an applied research or technical production that will describe the experiences lived in the organization based on scientific and methodological. It was possible to observe that the company offers QLW practices, but these are not enough to meet the needs of employees, and for this reason, actions such as standardization of benefits, regulation of working hours, standardization of individual protection equipament, gymnastics plan career, job and career plan, organizational climate research and motivational lectures.
\end{abstract}

Keywords: People management. Quality of life at work. Worker's health.

\section{INTRODUÇÃO}

Qualidade de vida no trabalho (QVT) são as ações que a empresa realiza com o intuito de implantar melhorias e inovações tanto na parte tecnológica como nas estruturais da empresa. A construção da QVT só ocorre quando a empresa enxerga os trabalhadores como parte da organização e que dependem deles para alcançarem resultados satisfatórios (FERREIRA, 2014).

A QVT visa diminuir o mal-estar e o exercício físico excessivo no trabalho, mas tem como objetivo maior manter um ambiente de trabalho que seja saudável, tendo como consequência uma maior qualidade na saúde do trabalho e, consequentemente, melhorando a 
produtividade dos colaboradores (ROMERO, 2013).

As empresas se preocupam com áreas financeiras, de produção, marketing e demais áreas da organização e, esquecem das pessoas e que sem elas esses propósitos não poderiam ser alcançados, por isso as empresas devem investir em estratégias pensando no trabalhador para gerar satisfação, saúde e bem-estar no ambiente de trabalho (GRAMMS; LOTZ, 2017).

Pensando nas pessoas a empresa tem a possibilidade de por meio de ações e programas implantados trazer resultados positivos para a empresa e para o trabalhador. Essas ações podem ser exercícios físicos, treinamento e desenvolvimento, ergonomia, ginástica laboral, benefícios entre outros que vão depender do que a empresa pode financeiramente oferecer (ALVES,2011).

$\mathrm{Na}$ visão de Limongi-França (2014, p.175) "existe crescente consciência ou percepção de QVT para o administrador, independentemente de sua área de atuação ou nível de formação", sabendo disso o objetivo dessa pesquisa é identificar se na empresa objeto de estudo existe práticas de QVT, e caso seja necessário propor melhorias, visando o bemestar dos colaboradores e, consequentemente, o aumento da produtividade e competitividade da organização.

\section{METODOLOGIA}

A abordagem utilizada neste estudo é o relato técnico, sendo definido como produto final

Figura 1. Perfil dos entrevistados.

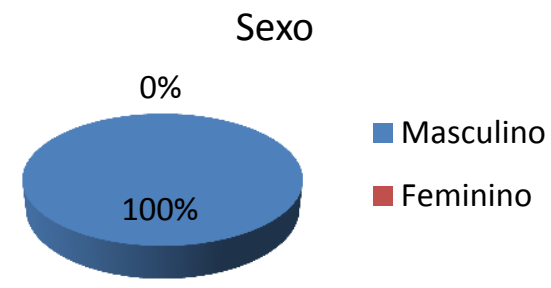

Fonte: Dados do Pesquisador (2018).

Quando questionados sobre condições ambientais de trabalho, nota-se que $50 \%$ dos entrevistados não estão satisfeitos com o de um trabalho, é uma pesquisa aplicada ou produção técnica que vai descrever as experiências vivenciadas na organização, nesse relato deve-se refletir tanto o pensamento do autor como deve ser escrito com base científica e metodológico (BIANCOLINO; KNIES; MACCARI; REBECHINI JUNIOR, 2012).

Para conseguir atingir o objetivo da pesquisa será usada a técnica de coleta de dados primária com a utilização de um questionário que na visão de Cervo (2007), usa-se com mais frequência o questionário para se coletar dados por que ele possibilita medir com mais exatidão o que se deseja alcançar na pesquisa oferecendo um resultado mais assertivo.

A coleta de dados foi por meio de entrevista, na qual Lima (2004) diz ser um encontro de duas ou mais pessoas que tem por objetivo obter dados, informações, opiniões, interpretações ou posicionamentos a respeito de determinado assunto. Sendo assim a entrevista ajudará a chegar numa visão mais geral da situação da empresa objeto de estudo.

\section{RESULTADOS E DISCUSSÃO}

No variável sexo foi identificado que $100 \%$ dos entrevistados são do sexo masculino. $\mathrm{Na}$ variável idade nota-se que $50 \%$ dos entrevistados tem idade entre 26 e 35 anos, 33\% tem entre 36 e 45 anos e outros $17 \%$ tem acima de 55 anos.

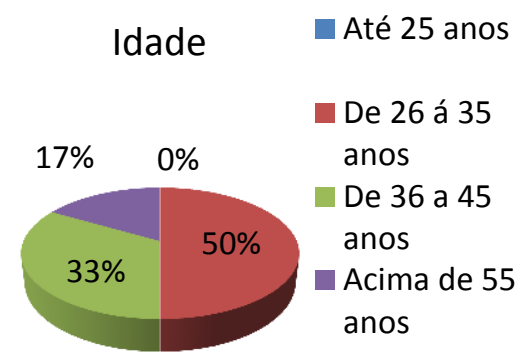

ambiente, já $33 \%$ estão satisfeitos e outros $17 \%$ estão parcialmente satisfeitos. 
Figura 2. Se as condições ambientais do local de trabalho são satisfatórias.

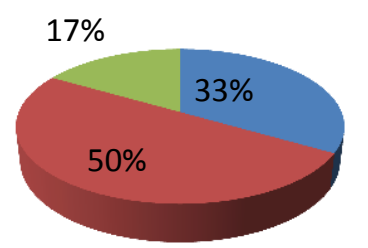

$$
\begin{aligned}
& \text { - Sim } \\
& \text { não } \\
& \text { Parcialmente }
\end{aligned}
$$

Fonte: Dados do Pesquisador (2018).

Com analise dos dados apresentados e por meio de uma observação na empresa, propõe-se que a organização ofereça uma área de descanso com mais conforto, visto que o refeitório e a área de descanso são áreas precárias.
Quando questionados sobre a organização oferecer Equipamento de Proteção Individual, pode-se notar que $50 \%$ dos colaboradores disseram que sim, porem $33 \%$ disse que não e outros $17 \%$ disseram que a empresa oferece parcialmente EPIs.

Figura 3. Se a empresa oferece Equipamentos de Proteção Individual (EPI).

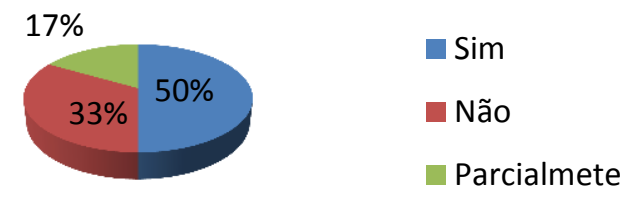

Fonte: Dados do Pesquisador (2018).

De acordo com os dados apresentados nota-se que a metade dos colaboradores relatou que recebe EPIs, porem $33 \%$ dos colaboradores relataram que não recebem. Com esses resultados propõe-se que a organização ofereça EPIs para todos os colaboradores e não só para alguns como foi observado no gráfico. Porém, por meio de uma entrevista com o gestor foi relatado que a organização oferece todo o tipo de EPIs necessário para desenvolver as atividades desde coletes, luvas, óculos e tampões de ouvidos.

Com isso foi notado uma falta de comunicação entre colaboradores e o gestor, e uma falta de comprometimento da parte dos colaboradores, visto que o gestor afirma que oferece todo tipo de EPIs e os mesmos não utilizam. A partir daí propõe-se que seja efetuada uma pesquisa de clima organizacional com o intuito de identificar os reais problemas da insatisfação dos colaboradores e com os resultados a organização possa intervir de forma mais assertiva em relação aos mesmos.

Quando questionados sobre jornada de trabalho, observa-se que $67 \%$ dos colaboradores não estão satisfeitos com sua jornada, porém $33 \%$ estão satisfeitos.

Figura 4. Se estão satisfeitos com a jornada de trabalho.

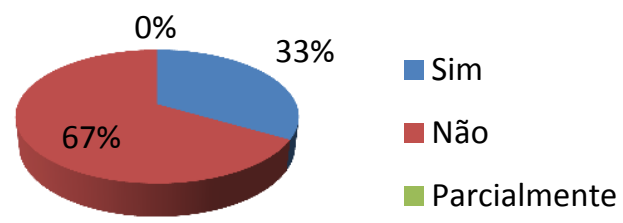

Fonte: Dados do Pesquisador (2018).

Com analise dos dados apresentados nota-se a insatisfação dos colaboradores com a sua jornada de trabalho, a jornada de trabalho dos colaboradores são dez horas por dia sendo uma hora de almoço e nove horas trabalhadas.
Foi constatada que essa hora a mais não está dentro da Consolidação das Lei do Trabalho (CLT), porque o colaborador pode trabalhar mais de oito horas por dia sendo que essa hora a mais seja paga como hora extra, tendo um limite de duas horas extras por dia. A legislação trabalhista 
estabelece, salvo em casos especiais que a jornada normal de trabalho é de oito horas diárias, sendo 44 horas semanais.

Propõe-se que o gestor estabeleça um horário de trabalho dentro das leis trabalhistas, ou pague o adicional de hora extra realizada por dia. Ou pode-se aumentar o horário de almoço de uma hora para duas horas sendo que assim passará a trabalhar oito horas diárias e não acarretará em insatisfação dos colaboradores.
Quando questionados sobre o salário ser justo em relação a função que eles exercem, $67 \%$ dos colaboradores disseram que não é justo, enquanto $33 \%$ disseram que sim. Em relação ao salário ser suficiente para atender as necessidades básicas, $67 \%$ dos colaboradores disse que não é suficiente enquanto $33 \%$ disseram que sim.

Figura 5. Se os colaboradores consideram seus salários justos e se atendem suas necessidades.

$$
\text { - Sim } \square \text { Não }
$$

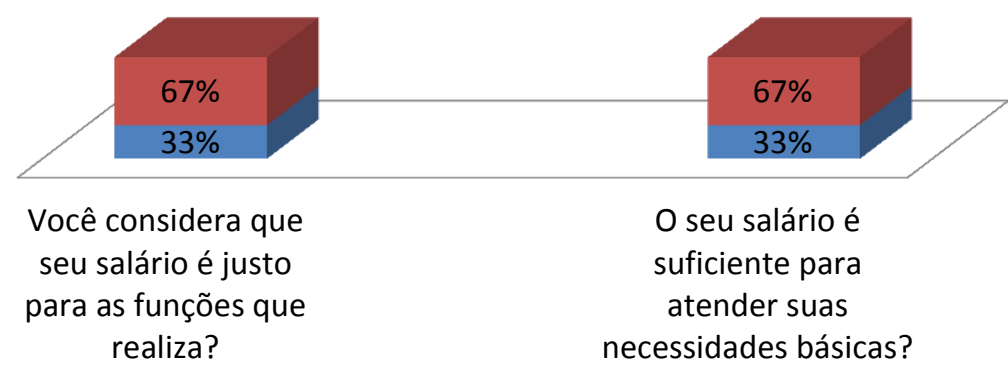

Fonte: Dados do Pesquisador (2018).

Com analise dos dados apresentados, propõe-se que seja formulado um plano de cargos, salários e benefícios para que assim a organização possa desde a integração do colaborador mostrar a ele quais são os seus direitos salariais para que não haja reclamações futuras.

Em relação ao salário não ser suficiente para atender todas as necessidades será proposto um treinamento de educação financeira para que os colaboradores possam aprender a como gastar apenas o que ganhar durante o mês

Quando questionados sobre a empresa oferecer algum tipo de benefício, $50 \%$ disseram que a empresa oferece benefícios, $33 \%$ disseram que oferece parcialmente e outros $17 \%$ disseram que não oferece.

Figura 6. Se a empresa oferecem benefícios aos seus colaboradores

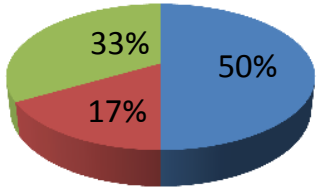

$$
\begin{aligned}
& \text { Sim } \\
& \text { Não } \\
& \text { Parcialmente }
\end{aligned}
$$

Fonte: Dados do Pesquisador (2018).

Com analise dos dados coletados nota-se que a metade dos colaboradores disse que não recebem ou recebem parcialmente. Em conversa com o gestor da empresa foi constatado que são oferecidos benefícios como vale transporte e cesta básica. Propõe-se com isso que a organização faça uma reunião com os colaboradores para conscientiza-los sobre o que é benefícios, para que os mesmos tenham consciência de que recebem sim benefícios e para que eles se sintam mais motivados em trabalhar na organização.

Quando questionados sobre estarem satisfeitos com os benefícios oferecidos pela empresa, $50 \%$ dos colaboradores disseram estar satisfeitos e $50 \%$ disseram que não. 
Figura 7. Nível de satisfação dos colaboradores em relação aos benefícios oferecidos.

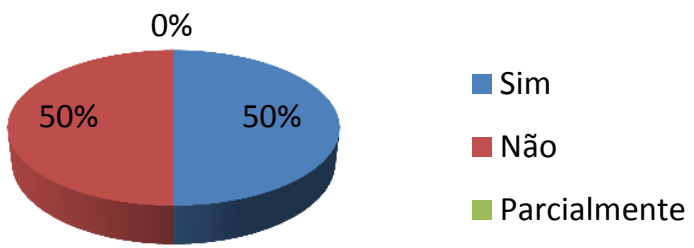

Fonte: Dados do Pesquisador (2018).

Com analise nos dados apresentados, notou-se que metade dos colaboradores estão insatisfeitos com os benefícios oferecidos pela empresa, com isso propõe-se que a organização ofereça um plano de saúde e odontológico visando uma maior satisfação dos colaboradores

Quando questionados sobre a organização oferecer ginástica laboral, nota-se que $100 \%$ dos colaboradores relataram que a organização não oferece ginástica laboral. Com isso propõe-se que a organização contrate um profissional da área para que realize uma vez por semana a ginástica laboral para os colaboradores. Visando um menor gasto para a organização propõe-se que a mesma procure universidades para fazer parcerias.

\section{CONSIDERAÇÕES FINAIS}

O presente estudo objetivou a verificar se na empresa objeto de estudo existem práticas de QVT e na falta dessas práticas propor melhorias para a empresa visando o bem-estar dos colaboradores e consequentemente da organização.

Desta maneira foi possível notar por meio da aplicação de um questionário para os colaboradores que a empresa oferece práticas de QVT, mas que não são suficientes por esse motivo surgiu as seguintes propostas a saber: padronização dos benefícios; regulamentação da jornada de trabalho; padronização de EPIs; plano de ginástica laboral; plano de cargos e carreira; pesquisa de clima organizacional e palestras motivacionais.

Com essas sugestões visamos uma melhoria na QVT dos colaboradores, pois sabe-se que colaboradores motivados e engajados produzem mais e melhor, e as empresas que investem na QVT tem um diferencial competitivo perante as outras.

\section{REFERÊNCIAS}

ALVES, E. F. Programas e ações em qualidade de vida no trabalho. INTERFACEHS - Revista de
Saúde, Meio Ambiente e Sustentabilidade, v. 6, n. 1, p. 60-78, 2011.

BIANCOLINO, C. A.; KNIES, C. T.; MACCARI, E. M.; RABECHINI JUNIOR, R. Protocolo para elaboração de relatos de produção técnica. Revista de Gestão e Projetos, v. 3, n.2, p. 294-307, 2012. Disponível em:

http://repositorio.uninove.br/xmlui/handle/1234 56789/331 . Acesso: 07 mar.2018.

CERVO, A. L. Metodologia científica. 6 ed. São Paulo: Pearson Prentice Hall, 2007.

FERREIRA, P. I. Clima organizacional e qualidade de vida no trabalho. Rio de Janeiro: LTC, 2014.

GRAMMS, L. C.; LOTZ, E. G. Gestão da qualidade de vida no trabalho. Curitiba: InterSaberes, 2017.

LIMA, M. C.; Monografia: a engenharia da produção acadêmica. São Paulo: Saraiva, 2004.

ROMERO, S. M. T. Gestão de pessoas: conceitos e estratégias. Curitiba: Intersaberes,2013.

Recebido para publicação em 15/06/2018

Revisado em 22/08/2018

Aceito em 27/08/2018 